\title{
PASSAGENS DO RURAL AO URBANO E PARTICIPAÇÃO SOCIAL: a sociologia política brasileira dos anos 60
}

\author{
Antonio Brasil Jr.* \\ André Botelho**
}

\begin{abstract}
Colocando em diálogo as pesquisas empíricas de Maria Isaura Pereira de Queiroz, Maria Sylvia de Carvalho Franco e Florestan Fernandes, realizadas nas décadas de 1950 e 1960 na Universidade de São Paulo, discutimos como esses três sociólogos trataram, mesmo que às vezes indiretamente, a questão da participação social, com o intuito de divisar o seu potencial teórico. Analisando as modalidades de participação do "homem comum" nas instâncias da vida política - nos processos eleitorais, nas relações com a burocracia do Estado, nos movimentos sociais, etc. -, Queiroz, Franco e Fernandes, de diferentes maneiras, situaram suas possibilidades e limites de acordo com as especificidades do processo mais geral de passagem do rural ao urbano no Brasil. Entendemos que a perspectiva histórica desses três autores, que mostram os efeitos de longa duração das raízes agrárias na conformação do mundo urbano, é fundamental para uma melhor compreensão dos dilemas de participação na sociedade brasileira contemporânea.

Palavras-chave: Pensamento social. Sociologia política. Maria Isaura Pereira de Queiroz. Maria Sylvia de Carvalho Franco. Florestan Fernandes.
\end{abstract}

As raízes rurais da sociedade brasileira constituem tópico central da Sociologia produzida no país desde as primeiras intepretações. Assim, no ensaísmo dos anos 1920-40, marcado por autores como Oliveira Vianna, Gilberto Freyre, Sergio Buarque de Holanda, Caio Prado Jr. e Nestor Duarte, dentre outros, vemos um movimento comum - embora, com sentidos diferentes em cada um deles - de volta ao passado agrário como chave de compreensão dos problemas do presente. Essas raízes rurais - e, por meio delas, também o legado das chamadas intepretações do Brasil - foram rediscutidas agudamente no que se poderia chamar do primeiro ciclo mais significativo de produção da Sociologia brasileira institucionalizada, ocorrida em torno da década de 1950 e que se desdobrou na década seguinte (Botelho, 2007, 2010; Brasil Jr.; Botelho, 2010).

\footnotetext{
* Universidade Federal do Rio de Janeiro (UFRJ). Departamento de Sociologia e do Programa de Pós-Graduação em Sociologia e Antropologia (PPGSA).

Largo de São Francisco, 1, sala 421. Cep: 20051-070. Rio de Janeiro - Rio de Janeiro - Brasil. antoniobrasiljr@gmail.com

${ }^{* *}$ Universidade Federal do Rio de Janeiro (UFRJ). Departamento de Sociologia e do Programa de Pós-Graduação em Sociologia e Antropologia (PPGSA).

Largo de São Francisco, 1, sala 415. Cep: 20051-070. Rio de Janeiro - Rio de Janeiro - Brasil. andrebotelho@digirotas.com.br
}

Embora compreendendo posições concorrentes, o debate, de alguma forma, corrobora um interesse comum renovado pela formação rural da sociedade brasileira, a qual parecia, então, constituir-se em dimensão crucial de diferentes pesquisas do período, como se essa formação modelasse a própria transição do rural ao urbano e as possibilidades futuras próprias do urbano. Esse interesse pelas raízes rurais da sociedade brasileira torna-se, assim, sociologicamente ainda mais significativo quando lembramos que, em meados do século passado, havia uma sensação generalizada de mudança social produzida pelos processos de industrialização, urbanização e desenvolvimento econômico em curso, bem como, no plano político, pela redemocratização do país, após a ditadura do Estado Novo (Botelho; Bastos; Villas Bôas, 2008).

A despeito da acelerada urbanização experimentada pela sociedade brasileira nas décadas de 1950 e 1960, parte significativa da agenda de pesquisas na Sociologia do período se orientou, de fato, para análises da vida social no mundo rural ou em pequenas localidades urbanas. Essa orientação encontrou, em parte, 
uma grande acolhida nos chamados "estudos de comunidade", o que rendeu uma ampla discussão a respeito de sua validade e legitimidade científica, cujos termos fogem aos propósitos deste texto (Jackson, 2009; Malaguti, 2013; Oliveira; Maio, 2011). Nosso foco está, antes, nas pesquisas do período que, ao contrário dos estudos que limitaram seu interesse às relações internas da comunidade, tomaram para si o desafio de perscrutar as relações dos grupos investigados com a sociedade inclusiva, especialmente aqueles que, desse modo, acabaram por discutir, direta ou indiretamente, a transição para uma sociedade urbano-industrial. Trata-se, então, de circunscrever mais uma perspectiva sociológica do que uma área de estudos ou temas de pesquisa, isto é, o interesse se volta para a transição do rural ao urbano como elemento teórico heurístico das pesquisas, mesmo quando, em seus aspectos empíricos, elas estejam, eventualmente, circunscritas aos novos cenários urbanos emergentes e aos novos atores sociais que neles se constituíam. A proposta aqui, portanto, é divisar o potencial teórico de uma abordagem sociológica que não desconecta a análise dos fenômenos do processo mais geral de mudança social.

Embora em menor número, também houve, no período, análises sobre as novas di• ڤ nâmicas sociais surgidas com o crescimento . urbano-industrial. $^{1}$ Se o interesse pelas bases agrárias da sociedade brasileira revela uma preocupação com o peso das estruturas sociais herdadas da Colônia - haja vista a fragmentação social e as desigualdades implicadas pelo latifúndio e pela escravidão -, a análise da ₹ participação das camadas populares urbanas \& em novas formas de atuação social e política oิ colocava em discussão as possibilidades aber$>$

क̊ ${ }^{1}$ Como lembrou Richard Morse (1990, p. 152), Georges Gurvitch, em sua passagem pela capital paulistana, "che$\stackrel{\pi}{\geq}$ gou a queixar-se de que a mais grave omissão dos socióస్ logos brasileiros era não explorar a cidade de São Paulo - como um laboratório social único". Através de outros arIJ gumentos, Morse entende que essa menor predominância gum dos estudos sobre o urbano em contexto de urbanização - avassaladora se deve à percepção de que as dinâmicas sociais emergentes nas cidades eram profundamente redefinidas em sua interação com as raízes rurais da sociedade ษ brasileira. tas pelo processo de urbanização no sentido de uma maior democratização da sociedade brasileira. Porém nem sempre a análise da constituição de atores sociais urbanos emergentes fez tabula rasa do peso da herança agrária. Sem desconsiderar a novidade inscrita na constituição das formas "modernas" de ação coletiva na sociedade brasileira, pesquisas importantes do período apontaram que o sentido do processo de urbanização ia sendo redefinido em interação com o padrão de transição do rural ao urbano assumido historicamente - o que, no mesmo passo, afetava os alcances e os efeitos da ampliação das formas democráticas de participação política. Dito de outro modo, ainda que preocupados com as formas de socialização e de ação coletiva em contexto propriamente urbano, alguns sociólogos e sociólogas se viram forçados a perceber que a margem de atuação inaugurada pela urbanização não era indiferente às estruturas e às assimetrias sociais herdadas do passado. ${ }^{2}$

Em geral tratada pela teoria sociológica como a transição entre tradição e modernidade, a percepção de que o urbano emergente no Brasil se redefine ao interagir com a matéria histórica do passado colonial pode ser localizada teoricamente como uma revisão das teses da Sociologia da modernização, que tendia a reduzir esse processo a uma passagem linear de um tipo de estrutura social a outro. E, nesse sentido, abre-se um diálogo com a tradição da Sociologia Política historicamente orientada (Smith, 1991). Os trabalhos de Reinhard Bendix (1996), Barrington Moore Jr. (1983) e Charles Tilly (1996), por exemplo, todos críticos à abstração da perspectiva histórica na análise das relações entre Estado e sociedade, chamaram a atenção para a diversidade de tra2 O caso talvez mais significativo seja o de Evaristo de
Moraes Filho, como já foi discutido em outra oportunida-
de (Brasil Jr., 2007, 2010). Embora tenha realizado uma
pesquisa de caráter sistemático que revelou a existência
de considerável movimento associativo operário nas pri-
meiras décadas do séc. XX nas principais cidades do país
- questionando, assim, a tese de que a legislação operária
seria uma simples outorga feita de cima para baixo -, o
autor não pôde desconsiderar o peso da estrutura agrária
na fragmentação das formas de pertencimento social e de
ação coletiva. 
jetórias de construção da cidadania e para a possibilidade de que a modernização possa gerar efeitos muito diferentes de acordo com os distintos pontos de partida e sequências históricas percorridas. Assim, é possível ver, em parte da produção brasileira, um tipo de Sociologia Política historicamente orientada, que chama a atenção para o fato de que as relações entre modernização e democratização não são universais, mas profundamente complexas e problemáticas em contextos não clássicos de revolução burguesa.

Para discutir esse legado da Sociologia brasileira dos anos 1950 e 1960, e sua capacidade de interpelação teórica à prática contemporânea da disciplina, propomos uma análise das pesquisas centrais de Maria Isaura Pereira de Queiroz, Maria Sylvia de Carvalho Franco e de Florestan Fernandes. Esses autores integram um repertório intelectual mais amplo com o qual vimos trabalhando nos últimos anos, em apreciações comparativas ou individuais (Botelho, 2007, 2009, 2013; Brasil Jr., 2013). ${ }^{3}$ Igualmente, vimos discutindo a problemática mais ampla das passagens do rural ao urbano noutros contextos intelectuais da tradição brasileira (Brasil Jr.; Botelho, 2010). A configuração aqui proposta, porém, além de inédita, permite a emergência e a discussão de novas questões e hipóteses como a que associa participação social à forma da transição para uma sociedade urbano-industrial.

A participação social é entendida aqui como a mobilização do "homem comum" no sentido dado ao termo por Charles Tilly (2013), isto é, redes de atores sociais conectados que carecem de controle sobre recursos substanciais (como, por exemplo, a força de trabalho de outras pessoas) - nos processos fundamentais da vida política. ${ }^{4}$ Com essa defi-

\footnotetext{
3 Outros trabalhos recentes também vêm tratando, em termos comparativos sincrônicos e diacrônicos, do potencial heurístico das formulações de Maria Isaura Pereira de Queiroz (Carvalho, 2010; Lopes, 2012), de Maria Sylvia de Carvalho Franco (Cazes, 2013; Hoelz, 2010; Malaguti, 2013) e de Florestan Fernandes (Bastos, 2013).

${ }^{4}$ Para um balanço sobre Charles Tilly, ver o dossiê organizado por Alonso e Botelho (2012).
}

nição, bastante genérica, evitamos considerar a participação social nos termos exclusivos da conformação de uma "esfera pública" participativa, definida em termos habermasianos, o que limitaria a análise basicamente ao período mais recente, que se inicia em fins da década de 1970, como vêm sugerindo, por exemplo, os trabalhos de Leonardo Avritzer (2000, 2012). Assim, vemos a participação social como as formas de relação do "homem comum" com as disputas que se dão no âmbito da vida política, seja diretamente, no nível das disputas pelo controle das instituições do Estado - como processos eleitorais, atuação das câmaras municipais, distribuição de cargos na burocracia estatal, constituição de partidos políticos, etc. -, seja indiretamente, como nos diferentes tipos de associativismo e movimentos sociais.

Em termos mais diretos, nosso interesse aqui é mostrar como, nas pesquisas sociológicas destacadas, foi tematizada a participação social como a mobilização do "homem comum” nas relações políticas. Essa apreensão da política tal qual é vivida pelo "homem comum" certamente aludia àquilo que Antonio Candido denominava de uma "rotação ética e social de atitude", que marcou especialmente, mas não exclusivamente, a Sociologia praticada na Faculdade de Filosofia, Ciências e Letras da Universidade de São Paulo. Em suas palavras, ali teve

o começo dos estudos sistemáticos sobre a sociedade, com preferência pela vida das classes subalternas, os grupos marginais, isolados ou oprimidos, segundo um espírito que superou a mera curiosidade ou o senso do pitoresco, que antes animavam a literatura e o ensaio voltados para esses temas (Candido, 1992, p. 24).

Mesmo quando a questão aparece de modo mais indireto nas pesquisas, ou até por isso, elas interessam à análise. Além de investigarem as formas de participação social através do ângulo dos atores sociais em suas pesquisas empíricas, Maria Isaura Pereira de Queiroz, Maria Sylvia de Carvalho Franco e Florestan Fernandes, cada um a seu modo, 
também inscrevem as possibilidades e os limites de atuação dos atores sociais no interior do processo mais amplo de formação histórica da sociedade brasileira e da passagem do rural ao urbano, cujos rendimentos analíticos nos interessam discutir aqui.

A formação rural da sociedade constitui dimensão central nas pesquisas de Maria Isaura Pereira de Queiroz e de Maria Sylvia de Carvalho Franco sobre diversos fenômenos da participação social na vida política brasileira. Mostram as sociólogas paulistas, em seus diferentes trabalhos, como aquelas raízes rurais atuam na modelagem de relações diretas, pessoalizadas e violentas na vida política, cujas bases sociais estariam em redes de reciprocidades assimétricas entre os diferentes atores e grupos sociais. Maria Isaura Pereira de Queiroz aposta nos estudos do meio rural devido às alterações das relações entre cidade e campo, pois, segundo ela, não caberia ao último um simples papel de coadjuvante, como muitos imaginavam. Além disso, insistindo na importância do trabalho empírico, Queiroz perscruta a sociedade camponesa não apenas em suas diversas manifestações, mas, acima de tudo, na movimentação de seus atores e nas relações que estabeleciam com a sociedade global (Botelho; Carvalho, 2011). Também na pesquisa realizada oै para seu doutoramento, defendido em 1964 na : Universidade de São Paulo, sob a orientação de Florestan Fernandes, Maria Sylvia de Carvalho Franco aposta na investigação das relações entre homens livres no Vale do Paraíba, ao longo do século XIX, para mostrar como, no Brasil, se constituiu um princípio mais geral de coor2. denação das relações sociais, denominado por a ela de "dominação pessoal”, que se desdobra no iे Estado e nas práticas capitalistas de mercado.

No caso de Florestan Fernandes, a passagem problemática e acidentada do rural ao urbano - ou, como o autor prefere, a formação de uma ordem social competitiva - forma o nervo de suas pesquisas e formulações teóricas. As especificidades históricas desse processo na sociedade brasileira explicariam os dilemas mais gerais da democracia no país. No que se refere à questão específica da participação social, podemos ver, em $A$ integração do negro na sociedade de classes (1965) - sua tese para a Cadeira de Sociologia I da Universidade de São Paulo, que mobilizou os materiais da pesquisa da Unesco sobre as relações raciais na capital paulistana -, a análise de um processo de urbanização que, ao reiterar desigualdades e assimetrias sociais herdadas do mundo agrário, limitava os canais de atuação autônoma por parte dos ativistas negros no interior dos movimentos sociais.

Ao colocar em diálogo esse conjunto de pesquisas realizado na Universidade de São Paulo entre 1950 e 1960, podemos avançar, igualmente, em uma melhor compreensão da sociologia política que ali se conformou. Em texto dedicado ao tema, Brasilio Sallum Jr. (2002) se concentrou na análise da "Sociologia Política do desenvolvimento", que emergiu a partir das pesquisas de Florestan Fernandes e de seus orientandos, em especial Fernando Henrique Cardoso. Por outro lado, estudando a formação de outra vertente da Sociologia Política brasileira, a que tomou não a questão do desenvolvimento e os conflitos do mundo da produção, mas as relações entre público e privado como núcleo da vida política e, portanto, do seu interesse, André Botelho (2007) incluiu as obras de Maria Isaura Pereira de Queiroz e Maria Sylvia de Carvalho Franco nessa agenda de pesquisas. Ao recolocarmos agora as obras desses três sociólogos paulistas em diálogo, cruzamos, portanto, agendas distintas também no que diz respeito a tradições intelectuais e de pesquisa no campo da Sociologia Política brasileira. Nossa proposta busca, assim, qualificar novas questões que apenas a consideração em conjunto dessas obras, isto é, dessas diferentes tradições intelectuais, permitem surpreender e evidenciar. Desse modo, certamente, também estamos chamando a atenção para as possibilidades de uma abordagem cognitiva de diferentes tradições intelectuais, e para os limites de uma perspectiva institucionalista das ideias que 
tenderia a minimizar as diferenças cognitivas entre Florestan Fernandes, Maria Isaura Pereira de Queiroz e Maria Sylvia de Carvalho Franco em função do seu pertencimento institucional comum à Universidade de São Paulo, ou que tenderia a atribuir essas diferenças, sobretudo, às competições em base igualmente institucionais travadas no interior dessa universidade.

Ao colocar em evidência a questão da participação social e da perspectiva histórica que informa as pesquisas dos três sociólogos destacados, pretendemos divisar outros significados heurísticos na produção sociológica paulista dedicada à análise da vida política, seja no que se refere às formas de dominação "pessoalizadas" e suas relações com as instituições políticas, questão fundamental em Maria Isaura Pereira de Queiroz e em Maria Sylvia de Carvalho Franco, seja na inquirição das formas de associativismo por parte dos setores subalternos em contexto de urbanização, ponto tratado por Florestan Fernandes. Assim, mostraremos a diversidade de orientações dessas tradições intelectuais, em que pese a orientação básica comum de entender a vida política associada ao movimento mais geral de transformação da sociedade brasileira. ${ }^{5}$ Por fim, com uma categoria mais abrangente, plural e menos normativa de participação social, esperamos tanto perscrutar as continuidades do fenômeno em momentos distintos da nossa sociedade, e não apenas as suas descontinuidades, quanto recolocar em discussão a hipótese das passagens do rural ao urbano na modelagem dessas formas de participação social.

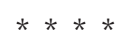

Em "O mandonismo local na vida política brasileira", de 1969, e "O coronelismo numa interpretação sociológica”, de 1975, recuperando trabalhos de campo realizados desde os

${ }^{5}$ Como igualmente é lembrado por Sallum Jr. (2002), podemos também mencionar as pesquisas de Azis Simão sobre o voto operário e a formação do proletariado em São Paulo como significativa dessa Sociologia Política que reconstituímos aqui. anos 1940-50, Maria Isaura Pereira de Queiroz introduz uma série de distinções analíticas que lhe permitem enfatizar a variedade da estrutura coronelística, bem como a diversidade de suas relações tanto com as estruturas sociais, econômicas e fundiárias, quanto com suas clientelas. São aspectos que, segundo sustenta (Queiroz, 1976, p. 165), teriam sido subestimados em Coronelismo, enxada e voto, especialmente em função da caracterização central de Victor Nunes Leal do "voto de cabresto". Nesse sentido, Queiroz começa por inverter a proposição de Leal, segundo a qual o "mandonismo" seria uma característica "secundária" do "coronelismo" (Leal, 1997, p. 41). Para a autora, o "coronelismo" é que seria uma forma histórica específica de "mandonismo local", esse, sim, o fenômeno que formaria a linha de continuidade da vida política brasileira ao longo tempo (Queiroz, 1976, p. 172). Além disso, para se contrapor à tese central de Leal, fará, em relação ao voto, aquilo que o catedrático de política da Universidade do Brasil fizera para caracterizar o coronelismo como um "sistema", isto é, entendê-lo como uma ampla rede de relações de reciprocidades assimétricas (Leal, 1997, p. 64). Nesse sentido, Queiroz argumenta que o voto integra um sistema complexo de reciprocidades, fundado na posse e na escassez de "bens de fortuna”, no qual a barganha política se tornava possível (Queiroz, 1976, p. 168).

Atenta aos fundamentos sociais da dominação política e sua variabilidade, Queiroz estrutura sua investigação em torno da categoria de "parentela", o que lhe teria permitido demonstrar a multiplicidade de níveis da dominação, segundo observou Glaucia Villas Bôas (2006, p. 145). As "parentelas" estariam na origem da estrutura da dominação política do coronelismo, envolvendo formas de sociabilidade e de conduta pessoalizadas. Trata-se de um núcleo extenso e espacialmente disperso de indivíduos unidos entre si por relações de parentesco de sangue, espiritual (compadrio) ou de alianças (uniões matrimoniais), relações econômicas e políticas, além de rivalidades e 
conflitos (Queiroz, 1976, p. 181). Devido à variabilidade socioeconômica das famílias que as compunham, as parentelas apresentariam estruturas internas bastante complexas, que iam de uma estratificação de tipo mais igualitário a outras mais hierárquicas. Por isso, se, nas zonas de latifúndio, a ascensão individual dependia, em grande medida, da aprovação do mandão local, nas de pequena propriedade, o carisma e as qualidades pessoais eram imprescindíveis para se atingir uma melhor posição social.

A solidariedade social forjada no interior das parentelas constitui, para Queiroz, um fator de, ao mesmo tempo, aproximação e distanciamento entre os indivíduos, e também de ascensão social. Ainda em "O coronelismo numa interpretação sociológica", define solidariedade como "união consciente ou não entre indivíduos e grupos em contato uns com os outros, que os faz aderir fortemente uns aos outros" (Queiroz, 1976, p. 190). Ela estaria na "base" do sistema coronelístico de dominação política, sendo ainda um dos três fatores de “conservação da estrutura brasileira de parentelas" Queiroz, 1976, grifo do autor). O segundo fator seria o conflito, definido como "oposição consciente ou latente entre indivíduos ou grupos, com a finalidade de subordinar ou destruir o opositor" (Queiroz, 1976). Conflito e (2) solidariedade convivem necessariamente, sur$\therefore$ gindo na sociedade brasileira "como duas faces da mesma moeda, não existindo uma sem a sua oposta, inerente, complementar e recíproca, por mais ambígua e paradoxal que seja "acomodação" às "diversas formas políticas que sucessivamente se instalaram no país - colônia, império, república. E se traduziram em ditados como este: 'para os amigos, tudo; para os inimigos, o rigor da lei”' (Queiroz, 1976).

$\mathrm{O}$ argumento de Queiroz sobre o "voto como posse", contra a ideia de "voto de cabresto" de Nunes Leal, estava fundamentado, como foi observado, em resultados empíricos de pesquisas de campo que ela realizou sistematicamente em Santa Brígida, no município baiano de Jeremoabo, entre 1954 e 1959. Seu interesse pela região é anterior, tendo surgido no contexto de um projeto de pesquisa no interior da Bahia, viabilizado por um convênio firmado entre o governo desse estado e a Columbia University, em 1949, sob a direção geral de Charles Wagley e Thales de Azevedo como diretor regional, além de Luiz de Aguiar Costa Pinto como consultor. Nele, coube a Maria Isaura o estudo sobre o folclore em Santa Brígida, que originou o livro Sociologia e Folclore: a Dança de São Gonçalo num povoado baiano, de 1958. Como "zona de sitiante", argumenta Queiroz, em Santa Brígida, a estrutura social tendia para uma configuração mais "igualitária”, em contraste com as regiões de "monoculturas de exportação ou de grandes criadores", nas quais, com base numa estratificação social diferenciada e rígida, a dominação política do coronel seria mais direta e mesmo mais violenta (Queiroz, 1976, p. 176). Fundamental, nos casos em que a barganha política era possível, seria o papel dos "cabos eleitorais", como um nível intermediário da estratificação e da dominação política que ligava aos coronéis os seus eleitores (Queiroz, 1976, p. 166).

Era o caso, em Santa Brígida, tanto de um fazendeiro, cuja simpatia advinha de seu desprendimento econômico e de sua maneira caridosa de ser, e de um dono de armarinho, indivíduo de algumas posses, que tinha a confiança e o afeto do coronel da região, o que lhe conferia algum prestígio. Ambos desempenhavam tanto o papel de mediadores entre a população sitiante e o partido, como no 
primeiro caso, ou entre aquela e um coronel distante, como no segundo. No entanto, a liderança que despontava de maior estabilidade era a do beato Pedro Batista, a quem os fiéis chamavam de "Padrinho", em decorrência de seus dons sobrenaturais, que o faziam líder carismático inconteste de um movimento messiânico que se instalara na região. Entre todos, sem dúvida, o beato, pelas características em que se funda sua liderança e pelo contingente de seguidores, era o mais atraente aos olhos dos coronéis. Isso porque, devido à sua crença nas qualidades sobrenaturais do líder carismático, a liberdade de movimento dos indivíduos é bem pequena e, por isso, é impensável votar em alguém diferente da indicação do Padrinho. Condição distinta era a daqueles que estavam fora da órbita de influência do beato e que, cientes da importância de seus votos, utilizavam-nos como "bem de troca" em busca de benefícios pessoais, tornando-os objeto de disputa entre coronéis e cabos eleitorais.

Assim, mostra Maria Isaura as relações sociais finas entre acesso à liderança, considerado como uma forma de "ascensão social", e as atividades políticas em comunidades menos estratificadas. Analisando as trajetórias dos três cabos eleitorais, conclui que, se o prestígio pessoal pode levar à liderança, é o "carisma" que, numa comunidade tão pouco diferenciada internamente como a de pequenos produtores autônomos, parece constituir um "verdadeiro canal de ascensão social” (Queiroz, 1976, p. 116). No Padrinho dos romeiros, como a socióloga tão bem percebeu, inscrevem-se e entrelaçam-se dois princípios distintos de legitimação da dominação (Weber, 2004), o "tradicional”, na autoridade pessoal que exerce, e o "carismático", manifesto na crença em suas qualidades extraordinárias: sua relação com os eleitores poderia até mesmo "independer de um esquema de dom e contradom” (Queiroz, 1976, p. 111).

Mas a "barganha" não se dá somente em uma direção: ela sela compromissos entre as partes que envolvem a sua observância, ainda que seja ela mesma suscetível de ruptura, in- clusive por parte dos sitiantes. Como observa Maria Isaura, o voto encerra, em si, um elo de favores e reciprocidades em sentido próximo ao apontado pelo antropólogo Marcel Mauss (2003) em seu "Ensaio sobre a dádiva". Argumenta Mauss que, mesmo nos atos mais gratuitos de liberdade, como a troca que envolve o "dom", existem condicionantes importantes que tornam a própria relação social de troca necessária e até obrigatória. Como observa, "essas prestações e contraprestações se estabelecem de uma forma sobretudo voluntária, por meio de regalos, presentes, embora elas sejam no fundo rigorosamente obrigatórias" (Mauss, 2003, p. 191). Ao invés de tomar o fato social como exterior e coercitivo, como fizera Durkheim (2013), Mauss o pensa como parte de um sistema formado por indivíduos livres, estabelecendo relações simétricas, não havendo, por isso, imposição, mas somente obrigatoriedade envolvida no ato da troca. Essa perspectiva coloca, em seu centro, a contingência como parte constitutiva da dinâmica social, uma vez que o próprio sistema de trocas pode ser interrompido por uma das partes integrantes, e a liberdade passa a ser apreendida como um espaço de possibilidades.

No caso dos sitiantes estudados por Maria Isaura Pereira de Queiroz, a liberdade que envolve a escolha e a barganha é circunscrita a partir do momento em que as partes efetivam a troca, e o voto dado passa a simbolizar adesão a um coronel e a seu grupo. Ainda que tal laço possa ser rompido - sendo sua observação e manutenção de grande valor pessoal e expressão da honradez individual -, espera-se do favor prestado sempre uma contrapartida. São as relações entre coronel, cabo eleitoral e sitiantes que expressam a integração, de "fato", da comunidade à sociedade global, em contraposição à ineficiente integração "legal” pelas instituições do Estado e seu aparelho burocrático. Há uma verdadeira "redefinição da política” em que

o voto é, pois, consciente, mas orientado de maneira diversa do que o voto de um cidadão de sociedade diferenciada e complexa; no primeiro caso, o voto é 
um bem de troca; no segundo caso, o voto é a afirmação pessoal de uma opinião (Queiroz, 1973, p. 120, grifos nossos).

Assim, se o voto integrava um "sistema" de trocas recíprocas nas áreas de pequenos produtores autônomos, as relações entre coronéis, cabos eleitorais e eleitores seriam realmente muito contingentes, pois nem "liderança" implicava posição de "superioridade", e nem era, em si mesma, garantia suficiente de "ascensão social" nessas pequenas comunidades rurais. Reconstituindo as trajetórias pessoais dos cabos eleitorais, Queiroz procura especificar as condições sociais que orientam as condutas individuais de modo articulado à estruturação da dominação política do coronelismo, perspectiva a partir da qual, ao contrário do que uma investigação somente "estrutural" ou "sistêmica” teria permitido, tornava-se possível, para ela, identificar o caráter dinâmico das relações de dominação política no Brasil. A vida social que se desenha em Santa Brígida, a partir de suas pesquisas, é, em suma, ilustrativa das possibilidades e limites de ação social nos contextos de dominação pessoal, questão que será retomada por Maria Sylvia de Carvalho Franco, ao questionar, contudo, as possibilidades de negação da dominação política pessoal por parte dos "homens comuns" em geral.

O argumento central da Sociologia Política de Maria Sylvia de Carvalho Franco é que a "dominação pessoal" seria incorporada, de modo constitutivo, às instituições públicas, isto é, que é a dinâmica da sociedade brasileira, definida pelo seu princípio mais geral, a "dominação pessoal", recria as instituições políticas e define o seu sentido possível na vida social (Botelho, 2013). Partindo, como assinalou Luiz Werneck Vianna (1999, p. 184), da tese de Max Weber sobre a singularidade da burocracia ocidental moderna, Franco entende que o processo de organização burocrática do Estado brasileiro, na primeira metade do século XIX, estava fundado "formalmente no princípio burocrático de obediência a um poder público abstratamente definido, legitimado e expresso por normas racionalmente criadas e legalmente estatuídas" (Franco, 1997, p. 121). Para o assentamento da autoridade pública, tratava-se, ao lado do emprego da força física e da guerra, de concentrar o aparelho tributário, dispondo de um "corpo de agentes disciplinados para o exercício metódico e despersonalizado das funções públicas" (Franco, 1997). Mas a burocratização da administração pública não se fazia num vazio de relações sociais, e, antes, encontrava, nelas mesmas, seus próprios limites. Noutras palavras, em sua interação com a sociedade, a burocratização teria sido rivalizada por fatores tão poderosos quanto o princípio racional-legal que, formalmente, parecia animá-la. O servidor público do município sintetiza exemplarmente a disputa que então se trava pela orientação das condutas dos indivíduos em sociedade entre, de um lado, aquele princípio racional-legal abstrato e longínquo, e, de outro, os "fortes interesses e influências que envolviam a sua vida de maneira imediata" (Franco, 1997). Nessa disputa entre solidariedades sociais, vence pragmaticamente a que prendia o servidor público ao seu próprio meio social via interesses materiais e também imateriais.

São, principalmente, duas as razões apontadas, com base nos materiais de pesquisa coligidos por Franco, para a demarcação pouco nítida entre as atividades privadas e públicas no âmbito das instituições do Estado. Em primeiro lugar, a precariedade estabelecida nas ordenações que regiam as práticas administrativas e sua fragilidade normativa para o conjunto da sociedade, e mesmo para o servidor, favorecia a que ele, no cumprimento de suas funções, continuasse orientando sua conduta no cotidiano pelo que o costume já havia assentado (Franco, 1997, p. 122-5). O outro fator decisivo do desenvolvimento da burocracia na administração pública, seguindo mais uma vez Max Weber, também ausente no Brasil do 
século XIX, foi, segundo Franco, o processo de “expropriação do servidor público dos meios materiais de administração, separando-se com nitidez os recursos oficiais dos bens privados dos funcionários" (Franco, 1997, p. 130). A principal razão para essa ausência estava na situação de extrema penúria em que se encontrava o Estado. Apesar de terem sido esboçadas algumas tentativas de solucionar o problema em conformidade com a organização burocrática que se queria implantar, "a possibilidade de tornarem-se práticas bem-sucedidas e utilizadas com regularidade foi nula” (Franco, 1997, p. 128).

Diante dessa situação paradoxal - já que a própria penúria crônica da administração pública que havia levado, desde 1834, à reorganização do aparelho tributário do Estado, impedia que esse processo se consumasse em termos burocrático-racionais -, a solução encontrada foi o "apelo direto ao patrimônio particular do cidadão comum ou do próprio servidor público" (Franco, 1997), solução que não apenas discrepava totalmente dos procedimentos característicos de uma ordem burocrática racional como reforçava o exercício personalizado do poder e o controle pessoal do patrimônio do Estado. Pois, nessas condições, argumenta a socióloga, ao invés de o servidor público tornar-se progressivamente um "executivo que apenas gere os meios da administração, manteve-se preservada a situação em que ele os podia controlar autonomamente, pois ele os possuía” (Franco, 1997, p. 131, grifo do autor). A articulação entre a debilidade material dos poderes públicos, o uso privativo dos aparelhos governamentais e as técnicas pessoais de dominação fundem Estado e sociedade. Esse entrelaçamento, por sua vez, constitui a própria condição da "dominação pessoal" que, como princípio mais geral de regulação das relações sociais no Brasil, desdobra-se na própria organização do Estado, unindo, necessariamente, público e privado.

Com sua discussão sobre a formação do Estado, Maria Sylvia de Carvalho Franco mos- tra, portanto, que a "dominação pessoal" seria incorporada às instituições políticas como princípio mais geral de regulação das relações sociais, de um modo constitutivo, o que se manifesta, fundamentalmente, no "exercício personalizado do poder". Nessas condições, como divisar a ruptura com a "dominação pessoal" por parte dos grupos sociais? Problematizando "ação" e "estrutura" nas relações de dominação política no Brasil, Franco logra apresentar uma visão integrada do próprio movimento geral da sociedade. Tal movimento, como um circuito fechado, ajuda a compreender como a dominação pessoal se enraíza nas instituições através da socialização e como os sentidos dessa socialização são afetados e podem ser reforçados através das próprias instituições, decorrendo desse processo justamente aquilo que a autora chama de "fechamento do mundo" (Franco, 1997, p. 94).

Atenta ao sentido sociológico das componentes sociais intersubjetivas presentes nas relações pessoalizadas e violentas de dominação política, Franco mostra que a "dominação pessoal", sustentada na contraprestação de serviços, favores e mercês de toda ordem, é "pessoal" justamente porque fundada numa identificação entre aqueles que dela participam integralmente como "pessoas", categoria que cria uma aparência de indistinção social corroborada, ainda, pelo "estilo de vida" simples da região desde o início do século XIX, quando a situação de penúria das condições materiais era praticamente generalizada (Franco, 1997, p. 115-9). O compadrio, por exemplo, é uma relação paradigmática da dominação pessoal, porque permite ou mesmo exige uma quebra aparente das hierarquias sociais entre aqueles que, pelo batismo, são unidos ritualmente num "parentesco divino" (Franco, 1997, p. 84-86).

Essa aparência de "igualdade" conferida pela categoria "pessoa" aos homens livres pobres, em oposição aos escravos, vistos como "propriedade" ou "coisa", é fundamental porque suas relações com os senhores não são vividas diretamente como uma relação de dependência. Essa relação se estabelece não ape- 
nas entre sitiantes e fazendeiros, mas também entre esses últimos e seus agregados, ou até mesmo com outras categorias sociais virtualmente menos dependentes deles, como tropeiros e vendeiros, todas elas submetidas à mesma trama de relações de fidelidades pessoais - ainda que a dependência direta pudesse ser superada via ascensão social em termos estritamente individuais (Franco, 1997, p. 65-114), como também assinala Queiroz.

As relações de dependência aparecem, antes, como uma "inclinação de vontades no mesmo sentido, como harmonia, e não como imposição da vontade do mais forte sobre a do mais fraco, como luta. Em consequência, as tensões inerentes a essas relações estão profundamente ocultas, havendo escassas possibilidades de emergirem à consciência dos dominados" (Franco, 1997, p. 95). Em síntese, diluindo as fronteiras entre público e privado, o favor emerge naquelas relações como sucedâneo e princípio negador dos direitos, como valor universalmente reconhecido e sancionado. É o favor que orienta as condutas dos indivíduos e grupos sociais nas interações, fundadas na estratificação social brasileira, de distribuição, aquisição e exercício do poder político. Além de serem assimétricas em termos de poder, as relações fundamentadas no reconhecimento I. mútuo entre fazendeiros e homens livres como ऽ. "pessoas" têm, ainda, efeitos sociais distintos quanto ao grupo social considerado. Afinal, seu atributo de "pessoa" garante aos homens livres pobres, no máximo, os favores de um senhor e, nessa mesma medida, lhes nega o reconhecimento da condição de portadores de direitos. Por outro lado, os senhores, além de se a encontrarem numa posição dominante nessas mesmas "associações morais" de contraprestação de lealdades, poderiam romper com elas de modo mais frequente.

Enfatizando a desigualdade de poder envolvida nas relações de dominação política pessoal, Maria Sylvia de Carvalho Franco sustenta que esse tipo de situação constituiria uma base social pouquíssimo "propícia para a orien- tação racional da ação" (Franco, 1997, p. 29), no que, então, se afasta de Maria Isaura Pereira de Queiroz e de sua caracterização da "racionalidade" da política, ainda que essa última, ao tratar do voto, sublinhe que ele é "consciente, mas orientado de maneira diversa do que é o voto de um cidadão de sociedade diferenciada e complexa". No primeiro caso, argumenta, “o voto é um bem de troca”; no segundo, "é a afirmação pessoal de uma opinião" (Queiroz, 1977, p. 178). Para Franco, por sua vez, um dos principais efeitos da dominação pessoal seria justamente a "asfixia da consciência política" (Franco, 1997, p. 89), situação na qual o voto não encontraria "condições para se expressar em mercadoria nem podia ser o resultado de uma autodeterminação enraizada na consciência de interesses autônomos" (Franco, 1997, p. 88). Por isso, aproximando-se, aliás, da caracterização das eleições de Vitor Nunes Leal (1997), Franco enfatiza que, mais do que na "manipulação do eleitorado" ou no "aliciamento de prosélitos", as técnicas empregadas para a conquista e manutenção do poder político incidiam, antes, no "processamento e no resultado das eleições” (Franco, 1997, p. 87).

$$
* * * *
$$

Em $A$ integração do negro na sociedade de classes, Florestan Fernandes analisa o que ele mesmo denomina de a emergência do "povo" na história da sociedade brasileira, vista a partir do grupo social que teve o pior ponto de partida no processo de transição do rural ao urbano - a população negra, constituída pelos antigos escravos e libertos na ordem escravocrata e senhorial (Fernandes, 2008, v. 1, p. 21). Como o próprio uso do termo "povo" esclarece, trata-se de uma análise que vai além da questão das relações raciais no Brasil, pois se almeja compreender, do ângulo do setor mais vulnerável da sociedade, os limites mais gerais da realização de uma ordem social democrática. Os dilemas enfrentados pelos negros e suas associações em São Paulo - cidade "que apresenta 
um desenvolvimento mais intenso, acelerado e homogêneo quanto à elaboração socioeconômica do regime de classes" (Fernandes, 2008, v. 1, p. 22) - possuiriam valor heurístico mais amplo, uma vez que os limites encontrados por esse grupo revelariam, com maior clareza, os dilemas da participação democrática enfrentados pelas camadas populares como um todo. $\mathrm{Ou}$, nos termos do autor, a partir da situação do negro, seria possível analisar o problema mais geral da "mobilização do homem da plebe para os papéis sociais e as situações sociais de vida da ordem social competitiva" (Fernandes, 2008 , v. 1). Trata-se do princípio teórico-metodológico de que, das margens do sistema social, apreender-se-iam com maior nitidez os princípios que conformam o processo social em seu conjunto (Bastos, 2002).

Se for verdade que o próprio Fernandes faz questão de ressaltar esta dimensão mais geral de sua pesquisa, ele não desconsidera que há especificidades inerentes à questão racial que não devem ser descartadas sem mais na reconstrução do associativismo negro em São Paulo durante a primeira metade do século XX. Simplificando o argumento do autor, podemos enumerar dois aspectos cruciais.

De um lado, o peso diferencial de uma herança cultural não apenas "rústica" e "tradicionalista" - da qual todos os grupos sociais da cidade ainda eram portadores, ainda que em graus diferentes -, mas de formas de socialização modeladas pelo regime da escravidão, o que acarretaria enormes dificuldades para uma ressocialização adequada às novas disciplinas requeridas pelo contrato de trabalho e pela racionalização das condutas exigida por uma economia de mercado. Ao se afirmar como homem livre, o ex-escravo tendia a repelir as posições sociais e as situações que se mostrassem análogas à condição anterior do cativeiro, aspirando a um tipo de liberdade incompatível com as novas condições de trabalho. Esse tipo de orientação teria sido fatal na competição com o imigrante europeu, que foi paulatinamente monopolizando as novas ocupações que se abriam na economia urbana de São Paulo. Embora o imigrante também se mostrasse limitado por um horizonte cultural "rústico", sua condição prévia de homem livre, associada ao desejo de "fazer a América" - isto é, trabalhar duro para constituir poupança -, tornava-o, frente ao negro, mais competitivo na disputa pelos postos de trabalho, mesmo no caso das ocupações manuais mais "degradantes". ${ }^{6}$ Com a quase inteira monopolização, por parte do imigrante, das novas posições sociais que se abriam com a urbanização, a maior parcela da população negra se viu condenada a ocupações ocasionais e mal remuneradas, o que tornava a combinação de pauperização, anomia e miséria um fardo a ser carregado por extensas camadas do meio negro paulistano. Para o autor, essa situação precária, em vez de favorecer o alargamento da solidariedade social, pulverizava os esforços e fragmentava as instâncias associativas, além de fomentar formas de individualismo predatório nas relações dos negros entre si. Nem mesmo o núcleo familiar, aponta Fernandes, teria se constituído de maneira integrada no meio negro de São Paulo, repondo o problema secular da desorganização das famílias negras, característica do regime da escravidão. As formas de "reciprocidade, de solidariedade e de responsabilidade" limitar-se-iam aos "níveis mais restritos da interação social", das quais não escapavam nem "mesmo o parentesco e o casamento" (Fernandes, 2008, v. 1, p. 290).

De outro lado, havia um padrão de relação entre brancos e negros que Fernandes denomina de "isolamento difuso", em contraste com o padrão de "segregação sistemática" existente, por exemplo, nos Estados Unidos.

6 "O negro e o mulato pretendiam as mesmas condições de vida e tratamento concedidas aos imigrantes, porém se obstinavam em repudiar certas tarefas ou, o que era mais grave, o modo de dispor de seu tempo e energias. Assim, a escravidão atingia o seu antigo agente de trabalho no próprio âmago de sua capacidade de se ajustar à ordem social associada ao trabalho livre. Tornava-se difícil ou impossível, para o negro e o mulato, dissociar o contrato de trabalho de transações que envolviam, diretamente, a pessoa humana. Ao contrário do imigrante, que percebia com clareza que
somente vendia sua força de trabalho, em dadas condiçôes de prestação de serviços, eles se ajustavam à relação contratual como se estivessem em jogo direitos substantivos sobre a própria pessoa." (Fernandes, 2008, v. 1, p. 46). 
Apesar da persistência, com enorme vigor, das desigualdades entre os dois grupos raciais no processo de transição para a sociedade urbana, esse padrão de "isolamento difuso" permitiria a existência de certas "aberturas" ou "brechas" na ordem social, isto é, havia a possibilidade de ascensão social - ultrasseletiva e em escala individualizada, pondera o autor, e quase sempre para níveis ocupacionais modestos - para algumas parcelas da população negra. Em São Paulo, isso teria propiciado o surgimento de uma "classe média" negra que, segundo Fernandes, com a mobilidade social ascendente, tendia a redefinir suas formas de pertencimento social em sentido estreito e egoístico, concentrando o melhor de sua energia e ambição na própria manutenção da nova posição conquistada - arduamente lograda, cumpre ressaltar -, apartando-se da maioria da população negra, condenada à miséria e à anomia (Fernandes, 2008, v. 1, p. 291, v. 2, p. 87-88).

Não por acaso Florestan Fernandes afirma que a existência de movimentos sociais no meio negro de São Paulo, entre as décadas de 1920 e 1930, seria uma verdadeira façanha histórica, tendo em vista, por um lado, o peso da combinação de anomia e miséria que grassava em amplas camadas dessa população - com seus efeitos negativos para o alargamento dos c) sentimentos de pertencimento e das formas de : ação coletiva - e, por outro, a falta de comunipotenciais lideranças, na medida em que os i canais de ascensão social levavam ao afasta-

尺ิ 7 " $[\ldots]$ a ascensão social do negro e do mulato sempre $>$ acarretou um mecanismo de redefiniçãa de interesses e if de lealdades. Com o desaparecimento gradual da ordem patrimonialista, essa tendência sofreu certas atenuações. Contudo, os indivíduos que se consideravam de 'elite' se isolavam da 'população de cor', esforçando-se por romper - qualquer ligação com pessoas ou com um estilo de vida I que pareciam degradantes. Ora, os elementos mais ativos nessa fase de transição se empenhavam em reaproximar aquelas 'elites' da 'massa' da população negra e mulata. Em particular, faziam enorme esforço no sentido de atrair para as manifestações coletivas o interesse, o apoio indireto ou a colaboração dos 'homens de cor' de prestígio.". como conseguir criar laços morais em condições tão adversas? Como engendrar formas de identificação compartilhadas num meio dotado de crescente heterogeneidade interna? Como tornar preferível a solução coletiva aos dilemas gerais do negro em meio a fortes pressões por soluções individualizadas, tanto no caso do negro pobre, por sua desorganização social crônica, quanto no do negro de "classe média”, por conta da possibilidade, ainda que estreita, de mobilidade ascendente? Ou, nas palavras do autor, como superar "o individualismo predatório e o egoísmo cego [como as] únicas armas eficazes na luta pela sobrevivência” (Fernandes, 2008, v. 2, p. 42)?

O processo de urbanização, aponta Fernandes, favoreceria um alargamento do horizonte cultural médio, propiciando o surgimento de novas formas de compreensão dos processos sociais por parte dos atores sociais. Além disso, a abertura da ordem social legitimaria um uso mais difundido do conflito como técnica de democratização social, como revelariam, a seu ver, "as reivindicações e as greves operárias dessa época [Primeira República]" (Fernandes, 2008, v. 2, p. 14). Esses dois fatores - o acréscimo de reflexividade social e o uso construtivo do conflito - seriam mobilizados pelos movimentos sociais no meio negro, seja para ensejar formas de ressocialização do negro em situação de pobreza e anomia para as novas exigências da sociedade urbana-industrial (Fernandes, 2008, v. 2, p. 17), seja para criar laços de solidariedade das "classes médias de cor" com os interesses do negro pobre, seja também no sentido de explorar, de modo sistemático, a “tensão aberta e o conflito [...] como 'armas de luta' e como técnicas de teor social construtivo" (Fernandes, 2008, v. 2, p. 23).

No fundo, esses dois fatores seriam conjugados pelos movimentos sociais na cena histórica. Pois, ao elaborarem o termo "preconceito de cor" como categoria inclusiva de pensamento - categoria, aliás, que foi efetivamente assumida por extensas parcelas do meio negro, como meio de um ajustamento mais reflexivo 
e inteligente à ordem social competitiva -, as associações procuravam persuadir seus membros de que os efeitos perversos da estereotipação negativa do negro atingiriam a população negra em seu conjunto (Fernandes, 2008, v. 2, p. 43-45, 114), estimulando formas de identificação coletiva como "minoria racial integrada” (Fernandes, 2008, v. 2, p. 57). Além disso, as associações negras teriam logrado relativo êxito em denunciar as desigualdades raciais persistentes e, no mesmo passo, desmistificar a existência de uma "democracia racial" na sociedade brasileira. Esse último ponto assume caráter decisivo no argumento de $A$ integração do negro na sociedade de classes (Fernandes, 2008 , v. 1, p. 304-327). A "ideologia racial dominante", gestada nas primeiras décadas do período republicano, ao sugerir que a ordem social estaria indistintamente aberta para brancos e negros, proscrevia pela base as possibilidades de legitimação política do protesto negro. Afinal, o "mito da democracia racial", ao difundir a crença de que não haveria preconceito racial no Brasil e, nesse sentido, nenhum problema a resolver no âmbito das relações raciais, desqualificava a reivindicação em prol do "levantamento econômico, social e cultural da gente negra” (Fernandes, 2008, v. 2, p. 79) - conforme o lema dos movimentos sociais -, tendo o efeito de agravar, em vez de resolver, a desigualdade secular entre brancos e negros.

Assim, com a crítica ao "mito", os movimentos sociais buscavam legitimar o conflito como forma de democratização das relações raciais, aumentando o grau de autonomia da população negra na reivindicação de seus próprios interesses. Ainda que tenham limitado o uso do conflito ao combate dos "resíduos do 'antigo Regime”” (Fernandes, 2008, v. 2, p. 43) no interior da sociedade de classes em expansão e consolidação - isto é, aceitaram os valores da sociedade de classes como uma ordem social aberta e democrática, procurando, porém, expurgá-la das deformações do padrão assimétrico de relações raciais herdado do passado -, a legitimidade que os movimentos no meio negro empregaram ao uso sistemático do conflito seria um elemento inequívoco de ampliação da participação política das camadas populares, em sentido democratizante. ${ }^{8}$

Ao apontar para as funções construtivas dos movimentos sociais no meio negro paulistano, na primeira metade do século XX, Fernandes não deixa de analisar, porém, seus inúmeros problemas, não só de ordem interna, mas também em sua relação com os processos mais amplos de transição do rural ao urbano. Em relação ao primeiro ponto, o mais decisivo seria a própria condição de pauperismo e anomia que atingia parcelas expressivas da população negra paulistana, o que rebatia em dois níveis distintos mais interligados. De um lado, isso impedia um maior controle interno, por parte dos membros das coletividades negras, dos processos de recrutamento e seleção de suas lideranças, que terminavam por agir, às vezes, de forma irresponsável ou unilateral (Fernandes, 2008, v. 2, p. 72). Para Fernandes, isso se revelaria, por exemplo, na adoção de formas autoritárias de liderança, caso da Frente Negra Brasileira (FNB) - a maior associação negra do período -, bem como na tentativa de converter a FNB em partido político, em 1936, o que acabou por precipitar sua extinção no ano seguinte, com o advento da ditadura do Estado Novo - pulverizando, por vários anos, os esforços de associação no meio negro paulistano (Fernandes, 2008, v. 2, p. 69-71). De outro, o afastamento da pequena "classe média de cor" em relação à maioria negra em condições de pobreza ou miséria tornava ineficiente a tentativa de uma atuação "monolítica" por parte dos movimentos sociais. Para Fernandes, teria sido mais construtiva a diversificação dos movimentos de acordo com os vários interesses

${ }^{8}$ Porém, o próprio "mito da democracia racial", por sua operação compatível com o padrão de "isolamento difuso" da população negra, implicava certa circunscrição do uso do conflito por parte dos movimentos sociais. Havia o temor de que, caso levado longe demais, o uso do conflito pudesse gerar "algo pior, como a segregação sistemática". Daí o "cunho moral" dado às manifestações e suas demonstrações de "conformidade com a ordem social existente", o que levava a uma "contenção consciente" do uso do conflito (Fernandes, 2008, v. 2, p. 43). 
sociais existentes no meio negro - tanto para o negro pobre quanto para o de classe média -, a fim de se alcançar uma articulação dos interesses da coletividade negra mais adequada à complexidade da sociedade de classes (Fernandes, 2008, v. 2, p. 93; Campos, 2013). Em relação ao segundo ponto - a relação dos movimentos com o processo mais geral de mudança social -, o autor mostra que a tentativa de abrir, in abrupto, a ordem social competitiva para a população negra esbarrou nos limites do caráter conservador assumido pela transição do rural ao urbano, já que, na esfera das relações raciais, o padrão "tradicionalista" de relação social assimétrica persistiria com grande vigor, contribuindo para a naturalização das desigualdades entre brancos e negros e condenando a atuação dos movimentos a uma profunda indiferença por parte da população branca. "O 'branco' não se levantou contra o 'negro' nem se opôs, abertamente, a seus movimentos reivindicatórios”. Porém, esclarece o autor, para que "eles lograssem êxito real, seria necessário que os 'brancos' compartilhassem, ativa e empenhadamente, dos propósitos de universalizar, indistintamente, os proventos econômicos e políticos da democratização do estilo de vida" (Fernandes, 2008, v. 2, p. 75). Sem apoio na sociedade inclusiva, as debilidades cै crônicas de ordem material e moral, existen: tes no meio negro de São Paulo, não dotariam os movimentos sociais da força requerida para pressionar, com a intensidade e a generalidade necessárias, pela transformação estrutural das relações entre brancos e negros.

Os dilemas enfrentados pelas associações negras exprimiram, segundo o argumena to de $A$ integração do negro na sociedade de 今 classes, os dilemas mais gerais da participação

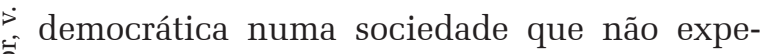
rimentou um processo clássico de revolução burguesa. E que, por isso mesmo, haja vista i o padrão conservador de transição ao mundo urbano, não abre às camadas populares o uso legítimo da competição e do conflito como instrumentos de democratização e universaliza- ção de direitos e garantias sociais. Apesar das especificidades da questão racial, conforme assinalamos brevemente aqui, a atuação das associações negras revelariam, com considerável nitidez, os limites impostos à participação política para o conjunto das camadas populares: os efeitos negativos da pauperização e da anomia nas formas de ação coletiva, a identificação com valores da ordem vigente em geral, associada aos fenômenos de mobilidade social ascendente - ainda que os canais para tal sejam estreitos -, bem como a pressão por soluções individualizadas para problemas de ordem coletiva e, arrematando o conjunto dos problemas, o confinamento dos benefícios da urbanização a um "circuito fechado", isto é, a parcelas reduzidas da população que monopolizam a renda, o prestígio social e o poder político.

$\mathrm{Na}$ década seguinte, em $A$ revolução burguesa no Brasil (1975), Florestan Fernandes articulou essa visão sobre o processo de mudança social no Brasil com uma análise de longa duração sobre a constituição do poder político no Brasil. ${ }^{9}$ A monopolização da renda, do prestígio social e do poder político por parte das camadas dominantes, ponto já identificado em A integração do negro, como discutimos acima, passou a ser entendida como constitutiva de um estilo especial de transformação capitalista, que Fernandes denominou de "autocrático-burguês" (Cohn, 2002). Assim, o fechamento das possibilidades de participação política autônoma por parte dos setores subalternos, exemplificada aqui através dos problemas enfrentados pelos movimentos negros em São Paulo, tal como são tratados pelo autor, seria reveladora da orientação privatista em relação ao poder, que não legitimaria o conflito por parte dos "de baixo" como mecanismo de democratização da sociedade.

\footnotetext{
${ }^{9}$ Para uma análise das continuidades entre $A$ integração do negro na sociedade de classes (1965) e A revoluçẫo burguesa no Brasil (1975), mas sem minimizar as diferenças entre os dois contextos (Cf. Bastos, 1987).
} 
Seria possível questionar a validade dessas pesquisas para uma compreensão sociológica contemporânea da participação social na sociedade brasileira, lembrando o caráter historicamente circunscrito dos fenômenos tratados por seus autores. Todavia, estamos interessados menos nos seus aspectos empíricos do que teóricos e analíticos. E as próprias pesquisas, como procuramos destacar, não deixam de assinalar, através das realidades empíricas e historicamente circunscritas de que tratam, o sentido analítico dos fenômenos associativos descritos para além das condições específicas que os originaram, permitindo colocar em questão as possibilidades efetivas de sua persistência, sob formas e com intensidades variadas. Se o conflito de gerações, como observou Barrington Moore Jr., lembrando o romance de Turgueniev, é constitutivo do caminho da compreensão histórico-sociológica cumulativa, dele não raro provém um prejuízo ingênuo, mas como muitas consequências: a "tendência para aceitar sem crítica a noção de que a atual geração realmente resolveu certas questões de modo mais ou menos permanente"; isto é, "que a investigação cientifica moderna 'demoliu' atualmente as interpretações mais antigas e que a adesão a qualquer aspecto importante das mesmas não é mais do que uma 'afirmação de mito religioso”' (Moore Jr., 1983, p. 501-502). Nesse sentido, dois argumentos nos ajudam a justificar a nossa proposta. Primeiro, porque entendemos que os desafios atuais de qualquer sociedade também estão associados à sequência do seu desenvolvimento histórico. Uma das conquistas heurísticas da Sociologia historicamente orientada, em geral, tem sido justamente a de permitir, na investigação das inter-relações de ações significativas e contextos estruturais, a compreensão das consequências inesperadas e também das pretendidas nas vidas individuais e nas transformações sociais (Botelho, 2014). Segundo, porque, ao concordarmos com o fato de que o sentido do conhecimento sociológico é também cumulativo, ainda que cronicamente não consensual, reconhecemos que o ree- xame constante de suas realizações passadas, inclusive através de exegeses de textos, pode assumir papel muito mais do que tangencial na prática corrente da disciplina.

O interesse de uma aproximação entre as pesquisas sociológicas de Maria Isaura Pereira de Queiroz e de Maria Sylvia de Carvalho, assim, como também discutido noutras oportunidades (Botelho, 2007, 2009), não se estingue em suas possíveis proximidades. As descontinuidades analíticas entre elas, aliás, tornamse particularmente identificáveis quando são exploradas as diferentes formulações de cada uma sobre a relação entre "ação" e "estrutura” no estudo da constituição, organização e reprodução das relações de dominação política pessoalizada. Maria Sylvia de Carvalho Franco, perguntando mais pelos efeitos da dominação pessoal no desenho das instituições políticas, percorre um caminho analítico que vai da socialização dos atores sociais à própria institucionalização, ao passo que Maria Isaura Pereira de Queiroz concentra-se apenas naquela primeira dimensão social, decorrendo, dessas diferentes posições, o debate entre elas sobre as metas e possibilidades da ação social no contexto de dominação política pessoalizada e, no limite, de negação da própria dominação por parte dos grupos sociais subalternos.

Mesmo demonstrando os limites da mudança institucional decorrentes da generalização da dominação pessoal como princípio de coordenação social, Maria Sylvia de Carvalho Franco não deixa de considerar as forças sociais que compõem dinamicamente a relação entre Estado e sociedade e, sobretudo, os atores sociais que as sustentam - como no caso do servidor público por ela analisado. Ao contrário, é justamente porque não presume a existência de estruturas institucionais dotadas de um sentido intrínseco e dadas de antemão, assim como Maria Isaura Pereira de Queiroz, que faz sentido pesquisar as ações contingentes e os significados a elas conferidos pelos "homens comuns". Guardando importantes afinidades com a Sociologia Política de Max Weber (2004), 
as bases sociais da dominação política são importantes nas pesquisas destacadas, tendo em vista não apenas o problema da "legitimidade", como também porque as próprias instituições ou outras formações sociais são compreendidas como resultados das ações e do entrelaçamento de ações de homens comuns que, ao atribuírem sentidos a suas ações, não deixam de levar em conta as próprias restrições da sua situação.

Já na perspectiva de Florestan Fernandes, como já havia assinalado Sallum Jr. (2002), confere-se pouca eficácia explicativa às dimensões institucionais do poder político. Mesmo quando o autor tematiza explicitamente o ponto, como em $A$ revolução burguesa no Brasil, é uma orientação mais geral em relação ao poder (a autocracia burguesa), e não as próprias instituições políticas que vêm ao primeiro plano da análise. ${ }^{10}$ Concentrando o melhor de sua teorização nos diferenciais de poder entre grupos e classes sociais em disputa, em A integração do negro na sociedade de classes, o autor mostra como os limites mais gerais da realização de uma ordem social democrática no Brasil se revelam de modo mais agudo nos setores que se encontram mais afastados do núcleo dinâmico de realização do capitalismo - no caso tratado no livro, a população negra egressa da escravidão. Apesar da reiteração es: trutural de uma situação de exclusão, miséria $\stackrel{\sim}{\circ}$ e anomia para grandes parcelas do meio negro paulistano, Fernandes assinala que isso não se traduz, automaticamente, em apatia política ou fatalismo, pois, mesmo em situações-limite, seria possível encontrar certas possibilidades

- ${ }^{10}$ Gildo Marçal Brandão (2007, p. 167-168) também enfati^ za o papel explicativo secundário atribuído por Florestan

¿ Fernandes à dinâmica própria das instituições políticas.

- Porém ressalta que, "apesar disso, a força do conceito [de

จ autocracia burguesa] - e do estilo de análise que o pressu-

$>$ põe - reside em que incorpora, mas não se confunde com

ธิ categorias como ‘autoritarismo' [...], não limita o olhar às

dimensões puramente institucionais do jogo político, bus-

$\stackrel{\pi}{\perp}$ ca captar uma dimensão estrutural - a presença estrutu-

๘ rante da economia e da sociedade no plano político [...].

Retomá-lo implica pôr o foco na natureza contraditória -

civilizatória e bárbara ao mesmo tempo - da experiência

\} societária e estatal em curso [no Brasil contemporâneo],

atravessada por uma estrutura sociopolítica que se flexi-

biliza para incorporar 'os de baixo' mas conserva alguns

de seus principais centros de decisão imunes à influência da democracia". de "abertura do mundo" e formas de inconformismo social ${ }^{11}$ (Fernandes, 2008, v. 2, p. 21).

Não vendo "ação" e "estrutura" como termos disjuntivos, mas como elementos dinâmicos que se redefinem a cada momento do processo histórico (Cohn, 2015), ele mostra como, a despeito da vulnerabilidade da população negra na estrutura de poder que se configurava na capital paulistana, seus movimentos sociais lograram levar adiante o conflito e, no mesmo passo, alargar uma compreensão crítica da situação racial no país. No entanto, justamente por não isolar a ação desses movimentos da estrutura mais ampla de desigualdades e de suas transformações na passagem do rural ao urbano, Fernandes tampouco recai numa visão "voluntarista" da atuação política dos atores sociais situados nas "margens", já que o próprio processo de exclusão relegava as demandas do protesto negro à quase total indiferença por parte da sociedade inclusiva (Brasil Jr., 2013, 2015).

Situando em chave histórica os processos sociais que conectaram os "homens comuns" à construção das instituições do Estado e à ampliação do espaço político - como a constituição de burocracias públicas, a extensão do direito de voto, o alargamento das disputas eleitorais, a emergência de movimentos sociais etc. -, as três pesquisas que colocamos aqui em diálogo viram que a participação social não pode ser dissociada das especificidades assumidas pela transição do rural ao urbano no país. Se o peso do passado é, em geral, mencionado nos trabalhos que tematizam os problemas crônicos da participação social na sociedade brasileira no presente, os trabalhos de Queiroz, Franco e Fernandes, ainda que de

${ }^{11}$ Em uma das passagens mais sensíveis de A integração do negro na sociedade de classes, Florestan Fernandes mostra que, mesmo em situações de desajustamento social crônico, constituíram-se formas "larvares" de inconformismo racial e de crítica às desigualdades entre brancos e negros. "[...] nos bares, nas esquinas e nos terrenos baldios, [as formas 'larvares' de agitação racial encontraram] canais de livre expressão verbalizada. Aquelas claques forneciam o palco em que as insatisfações materiais e morais podiam ser representadas diante da coletividade. Aos poucos, porém, esses dois tipos de inquietação larval evoluíram noutro sentido, encontrando polarizações dinâmicas que orientaram o inconformismo latente na direção de fins coletivos mais amplos, que requeriam consciência da realidade ambiente e atuação social organizada.” . 
diferentes modos, tencionaram especificar, de modo relativamente consistente, como as raízes rurais efetivamente afetaram os modos de dominação política e suas formas de contestação por parte dos "homens comuns". A fragmentação das formas de solidariedade e de ação coletiva, a inscrição de uma lógica privatista no próprio funcionamento das instituições do Estado e a naturalização de assimetrias sociais profundas, questões abordadas pelos três autores, redefiniram as formas de participação social, limitando o alcance do processo de democratização da sociedade brasileira.

Não se trata de negar, por óbvio, que houve mudanças sociais estruturais e uma ampliação inaudita das formas de participação nas últimas décadas, em particular após o fim do regime militar (Avritzer, 2016). O ponto aqui é chamar a atenção para a importância do processo histórico de transição do rural ao urbano e suas consequências de longa duração na sociedade brasileira. Essa advertência é particularmente urgente quando percebemos que o engajamento da "sociedade civil" e de suas formas de participação nos processos políticos está longe se ser unicamente democratizante, como os últimos acontecimentos do país têm mostrado quase à exaustão. A análise das formas de participação social não pode se limitar a correlacionar variáveis estruturais e mudanças institucionais, como se a urbanização e a democratização político-institucional levassem necessariamente a um círculo virtuoso de incremento associativo e maior controle democrático. Antes, na medida em que as próprias formas do urbano e a construção das instituições políticas interagem - de maneira tensa ou acomodatícia, a depender das forças sociais em disputa - com o legado de uma sociedade fragmentada, excludente e autocrática, uma perspectiva histórica é fundamental para se entenderem as reviravoltas na espiral de democratização do Brasil contemporâneo.

Recebido para publicação em 21 de janeiro de 2016 Aceito em 23 de abril de 2016

\section{REFERÊNCIAS}

ALONSO, Angela; BOTELHO, André. Repertórios de ação coletiva e confrontos políticos: entrevista com Sidney Tarrow. Sociologia \& Antropologia, Rio de Janeiro, v. 2, n. 3, p. 11-20, 2012.

AVRITZER, Leonardo. Democratization and Changes in the Pattern of Association in Brazil. Journal of Interamerican Studies and World Affairs, [S.1], v. 42, n. 3, p. 59-76, 2000.

. Sociedade civil e Estado no Brasil: da autonomia à interdependência política. Opinião Pública, Campinas, v. 18, n. 2, p. 383-398, 2012.

. Impasses da democracia no Brasil. Rio de Janeiro: Civilização Brasileira, 2016.

BASTOS, Elide R. A questão racial e a revolução burguesa. In: D'INCAO, M. A. (Org.). O saber militante: ensaios sobre Florestan Fernandes. Rio de Janeiro: Paz e Terra; São Paulo: Unesp, 1987.

. Pensamento social da escola sociológica paulista. In: MICELI, S. (Org.). O que ler na ciência social brasileira: 1970-2002. São Paulo: Sumaré; Brasília: ANPOCS, 2002. p. $183-230$.

. Gilberto Freyre e Florestan Fernandes: um debate sobre a democracia racial. In: MOTTA, R.; FERNANDES, M. (Org.). Gilberto Freyre: região, tradição, trópico e outras aproximações. Rio de Janeiro: Fundação Miguel de Cervantes, 2013. p. 262-278.

BENDIX, Reinhard. Construção nacional e cidadania: estudos de nossa ordem social em mudança. São Paulo: Edusp, 1996.

BOTELHO, André. Sequências de uma sociologia política brasileira. Dados, Rio de Janeiro, v. 50, p. 48-82, 2007.

. Dominação pessoal e ação na sociologia política brasileira. In: FERRETTI, S.; RAMALHO, J. R. (Org.) Amazônia: desenvolvimento, meio ambiente e diversidade sociocultural. São Luís: UFMA, 2009. p. 161-181.

. Passado e futuro das interpretações do país. Tempo Social, São Paulo, v. 22, p. 47-66, 2010.

. Teoria e história na sociologia brasileira: a crítica de Maria Sylvia de Carvalho Franco. Lua Nova, São Paulo, n. 90, p. 331-366, 2013.

. Political sociology: state-society relations. Current Sociology, [S.1.], n. 62, p. 868-885, Oct. 2014.

; BASTOS, Elide R.; VILLAS BOAS, Glaucia (Org.). $O$ moderno em questão: a década de 1950 no Brasil. Rio de Janeiro: Topbooks, 2008.

; CARVALHO, Lucas C. A sociedade em movimento: dimensões da mudança na sociologia de Maria Isaura Pereira de Queiroz. Sociedade e Estado, Brasília, v. 26, p. 209-238, 2011.

BRANDÃO, Gildo M. Linhagens do pensamento político brasileiro. São Paulo: Hucitec, 2007.

BRASIL JR. Antonio. Uma sociologia brasileira da ação coletiva: o debate entre Oliveira Vianna e Evaristo de Moraes Filho. 2001. Dissertação (Mestrado) - Instituto de Filosofia e Ciências Sociais, Universidade Federal do Rio de Janeiro, Rio de Janeiro, 2007.

Intelectuais e statemakers: Oliveira Vianna, Evaristo de Moraes Filho e a ação coletiva no Brasil. Estudos Históricos, Rio de Janeiro, v. 23, n. 46, p. 301-320, 2010.

Passagens para a teoria sociológica: Florestan Fernandes e Gino Germani. São Paulo Hucitec; Buenos Aires: Clacso, 2013.

. As ideias como forças sociais: sobre uma agenda 
de pesquisa. Sociologia \& Antropologia, Rio de Janeiro, v. 5, n, 2, p. 553-574, 2015.

; BOTELHO, André. Próximo distante: rural e $\overline{\text { urbano }}$ em populações meridionais e raízes do Brasil. In: FERREIRA, G. N.; BOTELHO, A. (Org.). Revisão do pensamento conservador: ideias e política no Brasil. São Paulo: Hucitec, 2010. p. 233-272.

CAMPOS, A. J. M. Interfaces entre sociologia e processo social: A integração do negro na sociedade de classes e a pesquisa Unesco em São Paulo. Dissertação de mestrado (sociologia). IFCH/Unicamp, 2013

CANDIDO, Antonio. A faculdade no centenário da abolição. Novos Estudos, São Paulo, n. 34, p. 21-30, 1992.

CARVALHO, Lucas C. Tradição e transição: mundo rústico e mudança social na sociologia de Maria Isaura Pereira de Queiroz. 2010. Dissertação (Mestrado) - Instituto de Filosofia e Ciências Sociais, Universidade Federal do Rio de Janeiro, Rio de Janeiro, 2010.

CAZES, Pedro. A sociologia histórica de Maria Sylvia de Carvalho Franco: pessoalização, capitalismo e processo social. 2013. Dissertação (Mestrado) - Instituto de Filosofia e Ciências Sociais, Universidade Federal do Rio de Janeiro, Rio de Janeiro, Rio de Janeiro, 2013.

COHN, Gabriel. A integração do negro na sociedade de classes. In: MOTA, L. D. (org.). Introdução ao Brasil: um banquete nos trópicos. São Paulo: Ed. Senac, 2002, $2^{\mathrm{a}}$ ed., p.385-402.

A margem e o centro: travessias de Florestan Fernandes. Sinais Sociais, Rio de Janeiro, v. 10, n. 28, p. 11-28, 2015.

DURKHEIM, Émile. O que é um fato social. In: BOTELHO, A. Essencial sociologia. São Paulo: Penguin Classics: Companhia das Letras, 2013. p. 179-190.

FERNANDES, Florestan. A integração do negro na sociedade de classes. São Paulo: Globo, 2008. v. 1.

A integração do negro na sociedade de classes. São Paulo: Globo, 2008. v. 2.

FRANCO, Maria Sylvia C. Homens livres na ordem escravocrata. São Paulo: Unesp, 1997.

JACKSON, Luiz C. Divergências teóricas, divergências políticas: a crítica da USP aos "estudos de comunidades". Cadernos de campo, São Paulo, n. 18, p. 273-280, 2009.

LEAL, Vitor N. Coronelismo, enxada e voto: o município e o sistema representativo no Brasil. $3^{a}$ ed. Rio de Janeiro: $\dot{\circ}$ Editora Nova Fronteira, 1997.

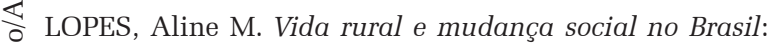
đadição e modernidade na sociologia de Maria Isaura $\Sigma$ Pereira de Queiroz. 2012. Tese (Doutorado) -Instituto de Filosofia e Ciências Sociais, Universidade Federal do Rio ลิ de Janeiro, Rio de Janeiro, Rio de Janeiro, 2012.
MALAGUTI, Paloma. A sociologia de Maria Sylvia de Carvalho Franco e os "estudos de comunidade" no Brasil. Dissertação (Mestrado) -Instituto de Filosofia e Ciências Sociais, Universidade Federal do Rio de Janeiro, Rio de Janeiro, 2013

MOORE JR., Barrington. As origens sociais da ditadura e da democracia: senhores e camponeses na construção do mundo moderno. São Paulo: Martins Fontes, 1983

MORSE, Richard. A volta de mcluhanaíma: cinco estudos solenes e uma brincadeira séria. São Paulo: Cia. das Letras, 1990.

MAUSS, Marcel. Sociologia e antropologia. São Paulo: Cosac \& Naify, 2003.

OLIVEIRA, Nemuel; MAIO, Marcos C. Estudos de comunidade e ciências sociais no Brasil. Sociedade e Estado, Brasília, v. 26, p. 521-550, 2011.

QUEIROZ, Maria Isaura P. Sociologia e folclore: a dança de São Gonçalo num povoado baiano. Salvador: Livraria Progresso, 1958.

O campesinato brasileiro: ensaios sobre civilização e grupos rústicos no Brasil. Petrópolis: Editora Vozes, 1973.

O mandonismo local na vida política brasileira e $\overline{\text { outros }}$ ensaios. São Paulo: Ed. Alfa-Ômega, 1976.

SALLUM JR., Brasilio. Notas sobre o surgimento da Sociologia Política em São Paulo. Política \& Sociedade, Florianópolis, v. 1, n. 1, p. 73-86, 2002.

SMITH, Dennis. The rise of historical sociology. Cambridge, UK: Polity, 1991.

TILLY, Charles. Coerção, capital e estados europeus. São Paulo: Edusp, 1996.

. Democracia. Petrópolis, RJ: Vozes, 2013.

VEIGA JR., Maurício Hoelz. Homens livres, mundo privado: violência e pessoalização numa sequência sociológica. 2010. (Dissertação) - Instituto de Filosofia e Ciências Sociais, Universidade Federal do Rio de Janeiro, Rio de Janeiro, 2010.

VIANNA, Luiz W. Weber e a interpretação do Brasil. In: SOUZA, J. (Org.). O malandro e o protestante: a tese weberiana e a singularidade cultural brasileira. Brasília: UnB, 1999.

VILLAS BÔAS, Glaucia. Mudança provocada. Passado e futuro no pensamento sociológico brasileiro. Rio de Janeiro: Editora FGV, 2006.

WEBER, Max. Economia e Sociedade. Brasília: Editora UNB, 2004. $2 \mathrm{v}$ 


\section{SHIFTS FROM RURAL TO URBAN AND SOCIAL ENGAGEMENT: Brazilian political sociology in the 1960's}

\author{
Antonio Brasil Jr. \\ André Botelho
}

This article discusses the question of social participation in the empirical researches of three sociologists, Maria Isaura Pereira de Queiroz, Maria Sylvia de Carvalho Franco and Florestan Fernandes, in order to detect its theoretical potential. In these researches, conducted in the 1950s and 1960s at the University of São Paulo, the authors, in different and sometimes indirect ways, studied the modalities of participation of "ordinary people" in political life, like electoral processes, relations with state bureaucracy, social movements and so forth. Also, they theorized social participation in the wider and specific context of rural-urban transition in Brazilian society, what conditioned its possibilities and limits. The historical perspective of these three authors, showing the long duration effects of agrarian roots in shaping the urban world, can bring a better understanding of participation dilemmas in contemporary Brazil.

KEYwORDs: Brazilian social thought, political sociology, Maria Isaura Pereira de Queiroz, Maria Sylvia de Carvalho Franco, Florestan Fernandes.

\section{LES PASSAGES DU RURAL À L'URBAIN ET LA PARTICIPATION SOCIALE: la sociologie politique brésilienne des années 60}

\author{
Antonio Brasil Jr. \\ André Botelho
}

Cet article traite de la question de la participation sociale dans les recherches empiriques de trois sociologues, Maria Isaura Pereira de Queiroz, Maria Sylvia de Carvalho Franco et Florestan Fernandes, afin de détecter son potentiel théorique. Dans ces recherches, menées dans les années 1950 et 1960 à l'Université de São Paulo, les auteurs, de différentes et parfois indirectes manières, ont étudié les formes de participation des «hommes communs» dans la vie politique, comme les processus électoraux, les relations avec la bureaucratie d'Etat, les mouvements sociaux et ainsi de suite. En outre, ils ont théorisé la participation sociale dans le contexte plus large et spécifique de transition rural-urbain dans la société brésilienne, ce qui conditionne ses possibilités et ses limites. La perspective historique de ces trois auteurs, montrant les effets de longue durée des racines agraires dans le monde urbain, peut apporter une meilleure compréhension des dilemmes de la participation au Brésil contemporain.

Mots-CLÉs: Pensée sociale brésilienne, sociologie politique, Maria Isaura Pereira de Queiroz, Maria Sylvia de Carvalho Franco, Florestan Fernandes.

Antonio Brasil Jr. - Doutor em Sociologia. Professor do Departamento de Sociologia e do Programa de Pós-Graduação em Sociologia e Antropologia da Universidade Federal do Rio de Janeiro. Publicou o livro Passagens para a teoria sociológica: Florestan Fernandes e Gino Germani (São Paulo; Buenos Aires: Hucitec; Clacso, 2013) e, mais recentemente, os artigos Fernandes e Alfredo Volpi: o moderno a partir de suas margens. Ciência Hoje, v. 56, p. 38-41, 2016; Improvisações orquestradas (resenha de 'Flores, votos e balas', de A. Alonso). Revista Brasileira de Ciências Sociais (Online), v. 31, p. 1-5, 2016; Entre trazos y tipos: la sociología en el Brasil y en la Argentina (Resenha de 'Sociologia no Espelho', de L. C. Jackson e A. Blanco). Prismas, v. 19, p. 254-258, 2015).

André Botelho - Doutor em Ciências Sociais. Professor do Departamento de Sociologia e do Programa de Pós-graduação em Sociologia e Antropologia (PPGSA) da Universidade Federal do Rio de Janeiro (UFRJ). Pesquisador do CNPq e da FAPERJ (Cientista do Nosso Estado). Editor de Sociologia \& Antropologia (PPGSA/UFRJ). Publicou, entre outros, Essencial Sociologia (2013) e De olho em Mário de Andrade: uma descoberta sentimental e intelectual do Brasil (2012). 
